\title{
The experience of stigma by service personnel during the COVID-19 pandemic in Sri Lanka
}

E Wickramasinghe, P de Zoysa, A Alagiyawanna, K Karunathilake, Y Ellawela, I Samaratunga, U Amarasinghe, N Fernando, S Karunarathna, L Wijesekara, K Weerasinghe, Z Mohideen, S Ala, R Ratnayake, P Karunapema

\section{Abstract \\ Introduction}

Stigma and discriminatory behaviours are common during pandemics. Stigma if not mitigated could result in varied negative psychological consequences in those who it is directed towards, as well as his/her associates.

\section{Objectives}

The objective of this study was to assess the dynamics of stigma experienced by ten different categories of people, the places and persons who expressed stigmatising attitudes and behaviours, adherence to COVID-19 related health instructions by the general public, and the aspects of the pandemic that had the most psychological impact in the above-indicated ten categories of people.

\section{Methodology}

We conducted a secondary analysis of already available data collected by the Directorate of Mental Health and Health Promotion Bureau of the Ministry of Health to formulate a communication campaign to combat stigma and discrimination during the COVID19 pandemic.

Results

Of the 4022 participants, a majority (53.7\%) were females, Sinhalese $(86.2 \%)$ and $17.3 \%$ were in the
25-29 year age category. Personnel working in health, security and other essential services and their family members experienced stigma and discrimination from the wider society, neighbours or media. Participants quarantined either at quarantine centres or in their homes, and their family members, also experienced stigma and discrimination. A majority of the general public reported avoiding places where health, security and essential service personnel gathered. Further, a majority of participants reported adhering to the COVID-19 related health instructions. The aspect of the pandemic that had the most psychological impact was the fear of contracting the virus.

\section{Conclusions}

Results indicated stigma and discrimination towards certain categories of people during the COVID-19 pandemic. It is essential that authorities take action to mitigate such instances, for instance by formulating media guidelines on reporting the pandemic an action that was implemented subsequent to these study results.

Key words: stigma, discrimination, COVID-19, pandemic, Sri Lanka

SL J Psychiatry 2021; 12(2): 15-21

\section{Introduction}

Stigma is defined as a negative attitude based on a distinguishing characteristic such as a health condition and could lead to discriminatory behaviour towards those who are being stigmatised (1). Mental illnesses, certain neurological diseases (e.g. epilepsy), obesity, disabilities, and communicable diseases (e.g. tuberculosis and severe acute respiratory syndrome) are some health conditions that are known to trigger stigma towards the affected and/or their family members $(2,3,4)$.

Stigma could be divided into two main types: social- and self-stigma $(5,6)$. Social-stigma refers to a negative 
attitude that motivate individuals to fear, reject, avoid, and then discriminate against people with a certain characteristic feature (5). Self-stigma occurs when the persons' stigmatised internalise these public attitudes, and as a result experience negative psychological consequences, such as low self-esteem (6). Regardless of the type of stigma, persons experiencing or being subjected to stigma face dire consequences, including mental health consequences $(5,6,7)$. Hence, mitigating stigma is essential.

During the COVID-19 pandemic, media reports of stigma towards certain categories of people were reported from across the world, including Sri Lanka (7). It is important to identify the dynamics of such attitudes and behaviours, particularly in highly infective outbreaks such as COVID-19 because, stigma by itself could act as a barrier for effective disease containment and equity of service provision (8). People who are at risk of infection or those who have suspected symptoms may hesitate to seek health care, not only because of the fear of the illness but also due to the stigma that surround it, which then poses a challenge for public health professionals to identify and control the spread of infection (1). Moreover, healthcare professionals and volunteers may get stigmatised by the public during infectious disease outbreaks, which may cause them distress and lead to a deterioration of services $(3,7,8)$.

In Sri Lanka, the present authors' observed that when media reports revealed the identity of those who contracted the COVID-19 infection, it sometimes led to an adverse psychosocial response from the community. This then influenced how some people perceived and behaved towards one another, particularly towards those infected with COVID-19, their families, and those quarantined. In addition, incidents of stigma and discrimination towards service personnel, such as health care professionals, were reported too, in Sri Lanka and globally $(7,9)$.

In order to prevent such health-related stigma and discrimination in the Sri Lankan setting, it is important to understand its dynamics within the unique cultural context of this country. In fact, such a necessity was particularly felt when the Ministry of Health's Health Promotion Bureau was planning a communication campaign to overcome stigma whilst empowering people to cope better during the COVID-19 outbreak in the country. Therefore, the Directorate of Mental Health of the Ministry of Health of Sri Lanka, in collaboration with the Health Promotion Bureau and experts in the fields of psychology and sociology, carried out a rapid online survey to assess the ground situation of stigma and discrimination during the COVID-19 pandemic. This survey aimed to assess: (i) the dynamics of stigma experienced by ten different categories of people, (ii) the places and persons who expressed stigmatising attitudes and behaviours, (iii) the adherence to COVID-19 related health instructions by the general public, and (iv) the aspects of the pandemic that had the most psychological impact on the above-indicated ten categories of people.

\section{Methodology}

\section{Study procedure}

The Mental Health Unit and the Health Promotion Bureau of the Ministry of Health collected data from several categories of people using an online survey. We utilized this anonymized data obtained from this survey conducted amongst 10 categories of people (i.e. healthcare personnel; security services personnel; other essential service personnel (e.g. Grama Niladari); family members of service personnel of health, security and other essential services; persons who have recovered from COVID-19; family members of persons recovered from COVID-19; persons in home quarantine; persons who had completed home or institutional quarantine; family members of persons in quarantine or who have completed quarantine; and the general public who did not fall into the above categories) who were above 20 years of age, and were living in Sri Lanka during the time of data collection. We conducted a secondary analysis of this already available data collected with the intention to formulate a communication campaign to combat stigma and discrimination during the pandemic.

\section{Survey Instrument}

As there was no validated instrument assessing pandemic-related stigma, the Ministry of Health, together with a group of experts in psychology, sociology and public health designed a 69 item instrument which contained five sections (Figure 1). It had been assessed for its content and face validity. The instrument had been made available in both Sinhala and Tamil languages. The data was analysed using SPSS.20.

\section{Ethical issues}

The results presented in this paper is an analysis of secondary data which was already collected by the Ministry of Health for a public awareness campaign and the authors obtained permission to use this data from the Ministry of Health, Sri Lanka. The data was anonymized and the Ministry of Health had obtained consent from the participants for collecting data and publishing the anonymized findings.

\section{Results}

A total of 4069 participants attempted the survey, while 4022 completed it (98.8\% response rate), within the targeted 10 categories. The majority were female (53.7\%), while $1.5 \%$ did not reveal their gender. Out of the total, $86.2 \%$ were Sinhalese and $5.7 \%$ were Tamil. Most participants were from Colombo (31.4\%). There were 
responses from participants from all the districts except Kilinochchi. Figure 2 shows the age distribution, and Table 1 shows the categories of persons who responded.

\section{The experience of service personnel}

The experience of health, security services (including the three forces and police) and essential service personnel being avoided/verbally maltreated for being involved in COVID-19 activities, and the places and persons who expressed those attitudes and behaviours are indicated in Table 2. In the domain of being avoided, healthcare personnel were avoided the most $(21.6 \%)$, and in the domain of experiencing verbal maltreatment, security personnel were subjected to this the most (15.2\%).

\section{The experience of family members of service personnel}

Family members of security personnel were the most $(13.6 \%)$ avoided/verbally maltreated, followed by family members of healthcare personnel (6.3\%). Family members of security and health personnel experienced such stigma mostly in the wider society, whilst essential services personnel experienced stigma mostly whilst shopping. Family members of both health $(50 \%)$ and essential services $(57.7 \%)$ experienced stigma from neighbours, whilst security personnel's family members (66.7\%) experienced stigma from the public as well as service users.

\section{The experience of persons recovered from COVID-19 or their family members}

Only one person who had recovered from COVID-19 responded to this survey. He had felt avoided whilst travelling in a three-wheeler. Of the nine family members who responded, $44.4 \%$ felt avoided/verbally maltreated due to being a family member of a person infected with COVID-19. They had experienced this most at the workplace and through social media.

Figure 1. Five sections of the questionnaire with 69 items

\section{Sections of the questionnaire}

1. Socio-demographic characteristics

2. Perception and experience of stigma and discrimination during COVID-19 (e.g. Did you experience any avoidance/verbal maltreatment from others?)

3. Effect on patient care provided by healthcare personnel due to stigma (e.g. Was the quality of care impacted due to a patients' respiratory symptoms?) and stigma-related patient care experienced by the general public (e.g. Did you feel that the care provided at hospital was affected due to your respiratory symptoms?)

4. Level of adherence to COVID-19 health instructions (e.g. washing hands)

5. Selected aspects of the COVID-19 which led to a psychological impact (e.g.: fear (of contracting COVID-19))

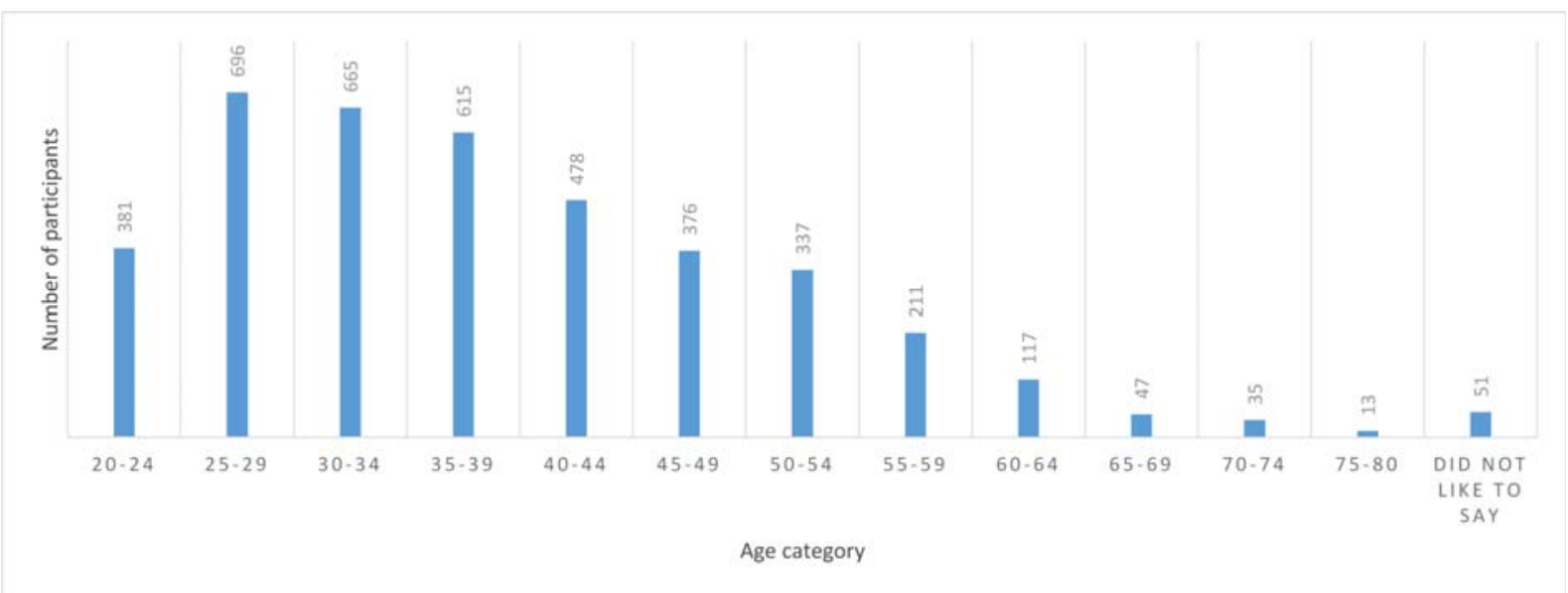




\section{Table 1. Categories of persons who responded to the survey}

\begin{tabular}{|c|c|c|c|}
\hline & Category of persons & $\mathrm{n}$ & $\%$ \\
\hline 1 & Healthcare personnel & 924 & 22.9 \\
\hline 2 & Security services (armed forces, police, private security etc) & 66 & 1.6 \\
\hline 3 & Other essential services & 614 & 15.3 \\
\hline 4 & Family members of health/security/essential services personnel & 288 & 7.1 \\
\hline 5 & Persons recovered from COVID-19 & 1 & 0.02 \\
\hline 6 & Family members of persons recovered from COVID-19 & 9 & 0.2 \\
\hline 7 & Persons currently in home quarantine & 25 & 0.6 \\
\hline 8 & Persons who had completed home/institutional quarantine & 30 & 0.7 \\
\hline 9 & Family members of persons in quarantine or completed quarantine & 28 & 0.7 \\
\hline 10 & General public & 2038 & 50.6 \\
\hline
\end{tabular}

Table 2. The experience of service personnel of being avoided/verbally maltreated for being involved in COVID-19 activities, and places and persons who expressed these behaviours

\begin{tabular}{|c|c|c|c|c|c|c|c|}
\hline & \multirow[t]{2}{*}{ Response } & \multicolumn{2}{|c|}{$\begin{array}{l}\text { Healthcare } \\
\text { personnel } \\
(n=924)\end{array}$} & \multicolumn{2}{|c|}{$\begin{array}{l}\text { Security services } \\
\text { personnel } \\
(n=66)\end{array}$} & \multicolumn{2}{|c|}{$\begin{array}{c}\text { Essential services } \\
\text { personnel } \\
(n=614)\end{array}$} \\
\hline & & $\mathrm{N}$ & $\%$ & $\mathrm{~N}$ & $\%$ & $\mathrm{~N}$ & $\%$ \\
\hline \multirow{2}{*}{$\begin{array}{l}\text { Perceived as being } \\
\text { avoided }\end{array}$} & Yes & 199 & 21.6 & 12 & 18.2 & 62 & 10.1 \\
\hline & No & 725 & 78.4 & 54 & 81.8 & 552 & 89.9 \\
\hline \multirow{2}{*}{$\begin{array}{l}\text { Subjected to verbal } \\
\text { maltreatment }\end{array}$} & Yes & 81 & 8.8 & 10 & 15.2 & 58 & 9.4 \\
\hline & No & 843 & 91.2 & 56 & 84.8 & 556 & 90.6 \\
\hline \multirow{9}{*}{$\begin{array}{l}\text { Place where } \\
\text { avoided }\end{array}$} & Work place & 40 & 20.1 & 2 & 16.7 & 17 & 27.4 \\
\hline & Home & 22 & 11.1 & 2 & 16.7 & 13 & 20.9 \\
\hline & Public transport & 23 & 11.6 & 2 & 16.7 & 6 & 9.7 \\
\hline & Three wheeler/taxi & 24 & 12.1 & 1 & 8.3 & 6 & 9.7 \\
\hline & While shopping & 49 & 24.6 & 1 & 8.3 & 12 & 19.3 \\
\hline & Wider society & 132 & 66.3 & 8 & 66.7 & 38 & 61.3 \\
\hline & Social media & 20 & 10.0 & 4 & 33.3 & 9 & 14.5 \\
\hline & Non-social Media & 23 & 11.6 & 5 & 41.7 & 8 & 12.9 \\
\hline & Other & 15 & 7.5 & 0 & 0 & 5 & 8.1 \\
\hline \multirow{6}{*}{$\begin{array}{l}\text { Person who } \\
\text { avoided/verbally } \\
\text { maltreated }\end{array}$} & Family members & 15 & 18.5 & 0 & 0 & 12 & 20.7 \\
\hline & Neighbours & 28 & 34.6 & 2 & 20 & 16 & 27.6 \\
\hline & Relatives & 15 & 18.5 & 1 & 10 & 10 & 17.3 \\
\hline & Friends & 16 & 19.8 & 2 & 20 & 5 & 8.7 \\
\hline & $\begin{array}{l}\text { Public or other people } \\
\text { using services }\end{array}$ & 36 & 44.4 & 3 & 30 & 21 & 36.3 \\
\hline & Other & 16 & 19.8 & 2 & 20 & 19 & 32.7 \\
\hline
\end{tabular}


Table 3. General publics' adherence to COVID-19 health instructions

\begin{tabular}{|l|c|c|}
\multicolumn{1}{|c|}{ Health instructions } & $\mathrm{n}(\mathrm{N}=4000)$ & $\%$ \\
\hline Washing hands with soap and water & 3810 & 95.2 \\
Not going out of the house other than for essential work & 3651 & 91.3 \\
Maintaining physical distance of more than a meter & 3357 & 83.9 \\
Not touching the face, mouth, nose and eyes & 3139 & 78.5 \\
\hline
\end{tabular}

\section{Table 4. Aspects of COVID-19 which was associated with the most psychological discomfort}

\begin{tabular}{|c|c|c|}
\hline Aspects of COVID-19 & $\mathrm{n}$ & $\%$ \\
\hline Fear of contracting COVID-19 & 2318 & 59.2 \\
\hline Fear of death due to COVID-19 & 960 & 35.1 \\
\hline Transport difficulties & 1123 & 34.8 \\
\hline Keeping physical distance from one another & 503 & 33.3 \\
\hline Not being able to socialize & 1027 & 28.7 \\
\hline Income loss & 1362 & 26.2 \\
\hline Closure of shops & 571 & 24.5 \\
\hline Difficulties in buying food, medicines and other essentials & 1373 & 14.6 \\
\hline Disturbance to children's education & 1305 & 12.8 \\
\hline Difficulties of looking after children & 180 & 4.6 \\
\hline
\end{tabular}

\section{The experience of persons (and their family members) who were in quarantine}

Twenty-five people who were in home quarantine had responded. Of them, $44 \%$ reported being avoided by others, whilst nine reported being verbal maltreated by neighbours. Among the family members of these 25 people, $32 \%$ reported being avoided/verbally maltreated by neighbours while they were at home.

\section{The experience of persons (and their family members) who had completed home or institutional quarantine}

Fourteen people reported being avoided, either in the wider society or in social or other types of media. Of them, $50 \%$ reported verbal maltreatment by neighbours. Twenty-nine people completed home or institutional quarantine. Family members of $17.2 \%$ of these 29 who completed quarantine, reported being avoided/verbally maltreated by neighbours, the wider society and/or relatives.

\section{Avoidance behaviours by the general public}

A majority of the general public (86.99\%) believed they should avoid places where health, security and essential service personnel are present. Also, 27.42\% believed they should avoid places where family members of these service personnel gathered. Further, $15.9 \%$ general public participants believed they should not allow their children to go to educational institutes, schools, transport services, playgrounds or parks where children of service personnel attend. Of the general public participants, $70 \%$ had some connection with a person infected with COVID-19 or a contact history. Of those, $26.03 \%$ believed they should avoid infected people or their family members. However, only $20.9 \%$ participants actually avoided such persons.

\section{Healthcare personnel's perceived effect on their patient care, and patient care experi- enced by the general public, due to COVID-19 related stigma}

Healthcare personnel were asked about their level of care of patients with respiratory symptoms, and $30 \%$ indicated 
that they provided poor patient care to those with respiratory symptoms. On the other hand, $25.6 \%$ of general public participants reported that they were not provided with the necessary care, as they felt they were misunderstood as COVID-19 patients due to their respiratory symptoms.

\section{Level of adherence to COVID-19 health instructions by the general public}

Table 3 indicates that the public had adhered to health instructions to a large extent.

\section{Psychological discomfort associated with aspects of COVID-19}

The fear of contracting COVID-19 was associated with the highest level of psychological discomfort (Table 4).

\section{Discussion}

The results of our analysis indicated that all three categories of service personnel (health, security and other essential services) and their family members experienced stigma from the wider society, media, and other sources. This may be a result of the manner in which the COVID-19 public health response was depicted in the media, at times implying an authoritarian stance taken by certain personnel. Another reason may be that these personnel were directly in contact with the infected, which raised the probability of them transferring the virus to others. However, majority of service personnel did not report experiencing stigma. This suggests that despite periodic reports in the media of stigma and discrimination, this survey data does not indicate it to be widespread.

When considering the place where stigma was most experienced, for all three categories of service personnel, stigma was experienced most in the wider society, as opposed to their work place or home. Stigma and discrimination may be more 'safely'shown in public areas, because identifying the perpetrator in these situations is not easy. Corroborating this hypothesis, when we explored who showed stigma the most, it was again the general public, as opposed to say, neighbours, relatives or friends. In addition, those (or their family members) who recovered from COVID-19, those returning from quarantine centres, or who were in home quarantine, also experienced some form of stigma, either in the wider society or through media. Hence, it appears that stigma is mostly seen in places and by persons whose identity cannot be easily established. Similar results have been observed elsewhere too (10). Stigma indicates detrimental social dynamics, and relevant authorities need to mitigate such attitudes and behaviours. For, without doing so, those with symptoms of COVID-19 (or other highly infectious diseases) may not seek treatment, and service personnel may feel demotivated due to being harassed by the public, despite the contributions they make. In fact, based on the findings of the survey on which this paper is written, guidelines for media reporting on COVID-19 patients was produced by the Ministry of Health and publicised through varied media. Moreover, communication material such as video clips and online posters were developed and widely disseminated across community platforms as measures to combat stigma during COVID-19 in Sri Lanka.

The results indicated that the general public adherence to COVID-19 health instructions are praiseworthy. However, these results may also have a self-serving response bias, and may need to be interpreted with caution. Interestingly, the most dominant psychological discomfort reported by a majority of participants was not death due to COVID-19, but rather fear of contracting the virus. Further, aspects such as not being able to socialise appeared to be more psychologically impactful to most, than difficulties in buying essential items or concerns regarding children. However, this maybe a reflection of the apprehensions of the mainly young adult age group that responded to this survey. Hence, this disparity in the age distribution of the study sample is a limitation, which could be overcome in future studies on this area.

\section{Acknowledgements}

We acknowledge the support of the Directorate of Mental Health, of the Ministry of Health, Sri Lanka, the Health Promotion Bureau, and experts in the fields of psychology and sociology who designed the survey questionnaire and shared the data; and the Deputy Director General (PHS II) Dr Susie Perera, and Director of the Non Communicable Disease Unit Dr Vindya Kumarapeli, for administrative support and guidance.

\section{Statement of contribution}

EW and PDZ designed the study, analysed and interpreted the data, and wrote and revised the manuscript. AA, KK and YE drafted the study and reviewed the manuscript for intellectual input. IS, LW, $\mathrm{KW}, \mathrm{SM}, \mathrm{SA}, \mathrm{RR}$, and PK ensured the integrity of the questionnaire items and was accountable for the completion of the study. UA and NF designed the questionnaire, worked on its translations, analysed the data, and reviewed the manuscript. SK and all authors have approved the final version of the manuscript.

\section{Declaration of interests}

None declared. 
E Wickramasinghe, A Alagiyawanna, Y Ellawela, U Amarasinghe, N Fernando, S Karunarathna, L Wijesekara, K Weerasinghe, Z Mohideen, S Ala, R Ratnayake, P Karunapema, Ministry of Health, Sri Lanka

P de Zoysa, Faculty of Medicine, University of Colombo, Sri Lanka

K Karunathilake, Faculty of Social Sciences, University of Kelaniya, Sri Lanka

I Samaratunga, Faculty of Social Sciences, University of Colombo, Sri Lanka

Corresponding author: E Wickramasinghe

Email: enoka7@gmail.com

iD http://orcid.org/0000-0003-2129-5496

\section{References}

1. Weiss M, Ramakrishna J, Somma D. Health-related stigma: Rethinking concepts and interventions. Psychology, Health and Medicine, 2006; 11: 277-87.

DOI: $10.1080 / 13548500600595053$

2. Brakel VW. Measuring health-related stigma-A literature review. Psychology, Health and Medicine, 2006; 11: 307-34. DOI: $10.1080 / 13548500600595160$

3. Stangl AL, Earnshaw VA, Logie CH, Brakel WV, Simbayi LC, Barré I, Dovidio JF. The Health Stigma and Discrimination Framework: a global crosscutting frame- work to inform research, intervention development and policy on health-related stigma. BMC Medicine 2019; 17:31. DOI.org/10.1186/s12916-019-1271-3

4. Baral SC, Karki DK, Newell JN. Causes of stigma and discrimination associated with tuberculosis in Nepal: a qualitative study. BMC Public Health, 2007; 7: 211. doi.org/10.1186/1471-2458-7-211

5. Parcesepe AM, Cabassa LJ. Public stigma of mental illness in the United States: a systematic literature review. Adm Policy Ment Health. 2013; 40(5): 384-99. doi:10.1007/ s10488-012-0430-z

6. Corrigan PW, Rao D. On the self-stigma of mental illness: stages, disclosure, and strategies for change. Canada Journal of Psychiatry. 2012; 57(8): 464-69. doi:10.1177/ 070674371205700804

7. Bagcchi S. Stigma during the COVID-19 pandemic. Lancet Infect Dis. 2020; 20(7): 782. doi:10.1016/S14733099(20)30498-9

8. Fischer LS, Mansergh G, Lynch J, Santibanez S. Addressing disease-related stigma during infectious disease outbreaks. Disaster Medicine Public Health Preparation, 2019; 13(56): 989-94.

9. Menon V, Padhy SK, Pattnaik JI. Stigma and aggression against healthcare workers in India amidst COVID-19 times: possible drivers and mitigation strategies. Indian Journal of Psychological Medicine 2020; 42(4): 400-01. doi: $10.1177 / 0253717620929241$

10. World Health Organization. Tackling COVID-19 fear and stigma, 2020. https://www.afro.who.int/news/tacklingcovid-19-fear-and-stigma (accessed on 20.04.2020). 